\title{
Integration Development Analysis of Cross - border Electric Merchants and Logistics Industry Chain in the Background of Industrial Convergence
}

\author{
Yibo $\mathrm{Hu}$ \\ Xi'an International University, Shaanxi, Xi'an, 710077, China
}

\begin{abstract}
In recent years, with the rise and development of Internet, the domestic logistics industry becomes flourish. The integration of the logistics industry with the cross-border business development is in line with the future development of domestic economic trends and requirements and it can promote cross-border electric and logistics industry to get better development. This paper firstly analyzes the conception and characteristics of cross-border electricity supplier and then analyzes the current development of cross-border electricity supplier, and then analyzes the interactive mechanism of cross-border electricity supplier and logistics related industry chain. Logistics-related industry chain and crossborder electricity providers are analyzed, and finally explore the specific measures to promote integration of logistics-related industry chain with the crossborder business.
\end{abstract}

Keywords: Industrial integration; cross-border electricity providers; logistics industry chain; integration and development

\section{Introduction}

Domestic economic development and changes in people's consumption patterns make the annual cross-border business volume steadily increased. There are many factors that can affect the development of electric business enterprises. For example, the efficiency of the logistics industry, the efficiency of the delivery, the 
efficiency of the service, the damage of the parcels and the effective tracking of the logistics records can directly affect the actual profits. A more complete crossborder business activity must include logistics, business flow, capital flow and information flow. Which is the development of electronic business logistics is a very important part. If the lack of cross-border electronic business this part of logistics, will not be able to get long-term development. The essence of crossborder electricity providers in the development period must be the same time the development of logistics-related industries, to minimize logistics costs, optimize its internal structure, in order to achieve long-term development of enterprises.

\section{The concept and characteristics of logistics-related industrial chain and cross-border electricity providers}

From a narrow perspective, cross-border electricity supplier is actually crossborder retail. But from a broad sense, cross-border electricity providers are actually foreign trade power providers. Cross-border electronic business refers to the two different regions of the main electronic trading platform, after the buyer through the electronic platform for payment, and the seller through the crossborder logistics to the goods by mail to the buyer address until the buyer sign. This series of activities constitute the cross-border business as a whole business. At present, the domestic has matured cross-border business platform for the two main types, one is the B2B model and there is a B2C model. These two models are intangible, anonymous and global and it has very many types of goods, information technology is changing very fast and so on. Logistics industry chain is generally composed of logistics and transportation related industries and its derivatives industry, which mainly includes transportation, logistics technology, information technology, logistics, real estate and logistics equipment. The logistics industry chain with the integration of service objects and each link in the industry chain are closely integrated.

\section{The current development of cross-border electricity supplier}

According to statistics, the first half of 2015, domestic cross-border electricity providers, the total transaction volume, up to 2 trillion yuan, an increase of $42.8 \%$, this amount accounts for about $21 \%$ of China's foreign trade. In 2016, the total amount of cross-border electricity providers reached 6.8 trillion yuan. These data indicate the word 2011, China's current cross-border electronic business to complete the total transaction volume increased by 30 percentage points per year. The current domestic cross-border electricity providers in the rapid development stage, which is because in recent years, domestic traditional foreign trade shrinking phenomenon, which created cross-border electronic business development opportunities, it has become China's foreign trade development in a new direction. And this direction has been related to confirm the central 
authorities. Cross-border electric business in China can help China's foreign trade development and structural optimization and upgrading. However, according to market data in recent years, the domestic cross-border electricity suppliers have been in the imbalance in the import and export situation. For example, B2B mode in the total amount of which accounted for $91.9 \%$, while the $\mathrm{B} 2 \mathrm{C}$ can only account for $8.1 \%$. Thus, B2B to achieve the volume of transactions up to B2C trading volume as much as 11 times and imports were significantly less than exports. Data show that imports are only one-sixth of exports, indicating that the domestic cross-border electricity providers to export-based electricity providers. While B2C this model presents a small amount of fragmentation and characteristics of domestic consumer habits which have a direct relationship.

\section{The interaction mechanism to improve the cross-border electronic business and logistics-related industry chain}

First, the logistics industry and cross-border electronic business there is a dependency relationship. Cross-border electricity providers want to be developed and it must be related to the logistics industry as a basis for development, and only the logistics industry for the electricity providers to provide the appropriate logistics services, cross-border electronic business transactions can make the resources and goods in the world of transmission. On the contrary, cross-border electricity providers are also related to the logistics industry has an important role. As we all know, the logistics industry as early as cross-border electricity providers have existed before, but when the level of its operation is low, until after the emergence of e-commerce, it really into people's vision. It can be said that the logistics industry is based on the development of e-commerce. Second, the logistics industry with the cross-border business has a mutually reinforcing relationship. Today, the information industry with the gradual improvement of the information network, which invisible to promote cross-border development of electricity providers, making the cost of logistics effectively reduced. At the same time, cross-border electronic business in the country continue to promote the deepening development of the logistics industry structure changes, making the types of logistics industry gradually increased, and its business functions continue to improve.

\section{The integration analysis of logistics-related industry chain with the cross-border electricity providers}

\subsection{The technical integration is as a whole development basis}

New technologies have created the conditions for innovation in traditional industries. Therefore, the new technology as the basis for the integration of the two sides, we can optimize the industrial structure, while promoting the 
development of both sides. Therefore, the power of this industry was born. Current cross-border electricity providers can provide users with different levels of related services, and this form gradually replaced the previous international trade. Logistics industry in the promotion of new technologies and it is moving forward in the modernization efforts.

\subsection{The business integration is a concrete manifestation}

Cross-border electricity providers can provide relevant information for international trade, but also can promote the two sides' related transactions, in addition to meet the logistics related to transport services. In the service period, users can use the platform to understand cross-border electricity providers to provide some of the related services [1-2]. Under normal circumstances, crossborder electricity providers will be full of logistics related services to the logistics industry, although it reflects the logistics industry with the cross-border business integration phenomenon, but this is only a simple business relationship.

\subsection{Operational integration plays a role of carrier}

The logistics industry with the cross-border business in the business integration is just a simple business relationship. In fact, the two sides are still two separate individuals, which makes cross-border electronic business logistics industryrelated capacity is not deep, while the logistics industry is also a little knowledge of user information. This situation can easily lead users to question their quality of service. Therefore, the logistics industry with the cross-border electricity providers must be related to integration, information sharing, the two sides in the operation of the integration, can help users understand the logistics business platform related information, and you can see the logistics related transaction information to this to enhance user satisfaction, while promoting the integration of the development of both sides.

\section{The specific measures to promote logistics-related industrial chain with the cross-border business integration}

\subsection{Improve the integration development policies}

In recent years, the Chinese government has gradually adjusted the policies related to settlement, payment and information management. Up until now, the existing domestic policies related to the logistics industry and cross-border electricity business are still relatively few and some even missing. For example, in terms of taxation settings, can not meet the needs of the situation. As the current domestic development of the integration of the two sides less relevant policies, making the two sides during the integration of certain problems in development, so the relevant departments must be based on the actual situation of 
the two policies related to the two sides during the integration of contradictions Resolve.

\subsection{Create the related trust mechanism}

In recent years, because the logistics industry with the cross-border business there is business, which makes the two sides often appear in the interests of certain friction. Therefore, conflict of interest is the main cause of mutual distrust between the two sides. Thus, the two sides related to the trust mechanism must be established on the basis of a reasonable distribution of benefits. To carry out a reasonable distribution of interests, first, we must choose to mutually beneficial win-win cooperation programs and distribution programs. Second, choose the appropriate form of fund transfer. In the distribution of benefits and cooperation programs established during the government can come forward to mediation until the two sides are satisfied. The cash flow, you can use third-party payment platform to achieve. Therefore, making the overall flow of logistics during the period, in a transparent state, effectively avoid the logistics and power companies' suspicion of both sides [3-5].

\subsection{Through the integration of the two business aspects to improve the harmony}

First, is to make express delivery business with cross-border electricity providers to integrate, including overseas and domestic courier two aspects. If you can achieve domestic and foreign business integration is bound to form a win-win situation, but also can enhance the overall logistics efficiency, to help logistics and cross-border electricity business-related enterprises to achieve profit growth. In general, freight logistics has always been in the overall logistics system occupies an important position, if from a world trade perspective, it is both extraordinary missions. As a result, cross-border electricity providers can promote their own development through cooperation with the freight-related enterprises in business. Third, the postal service will be integrated with crossborder electricity providers, and the development of integrated programs. Crossborder e-business can optimize the logistics structure by integrating with the postrelated business, thus reducing the existing intermediate aspects of many logistics to improve logistics efficiency.

\section{Conclusion:}

In summary, in the business integration of the logistics industry and cross-border business operators, there are more interference factors and it is more extensive, the future of the integration must have diversified development path, but they both can not from the open market-oriented role. At this stage, the integration of technology, business and operational aspects of logistics-related industrial chain and cross-border electricity providers promote the in-depth development. In the face of the problems during the logistics industry and cross-border electronic 
business we must improve the relevant policies to enhance the harmony between the two sides, and through business innovation to enhance the depth of the development of the integration so as to enable both sides to get in-depth development to achieve the ultimate goal of integration development.

\section{References}

[1] Xiao Min Chen. Eco-commerce logistics industry chain integration model analysis. Management, 55(12), pp.68-70, 2011

[2] Zhu Qisong, Zhu Hui-ting. Analysis of Cross-border Electric Merchants Development in the Context of Internet. Journal of Sichuan University of Science \& Technology (Social Science Edition), 8 (5), pp.87- 91, 2013

[3] Ren Ling. From the industrial transition perspective, the logistics industry chain and cross-border electronic business integration development. Business Economics Research, 12(10), pp. 18- 20, 2012

[4] LI Jia-ting, Fan Zhongjun, Wang Yusha. Analysis of China's Cross-border Electronic Commerce Logistics Model and Its Market Research. Logistics Technology, 9(6), pp.58-61, 2011

[5] Zhao Guanghui. An Empirical Study on the Development of China's Logistics Finance in the Background of "Internet +" - Taking Shunfeng and Tengbang as Examples. Journal of Qujing Normal University, 8(4), pp.85-87, 2014 